PALABRAS CLAVE

Pobreza urbana

Historia

Crisis económica

Clase media

Condición social

Política social

Estudios de casos

Zonas metropolitanas

Argentina

Gabriel Kessler

Profesor Adjunto,

Universidad Nacional de General

Sarmiento.

Investigador del Consejo Nacional de Investigaciones

Científicas y Técnicas (CONICET)

○ gkessler@dd.com.ar

María Mercedes Di Virgilio

Profesora Adjunta,

Universidad de Buenos Aires.

Investigadora del CONICET

œ mdivirgilio@fibertel.com.ar
REVISTA DE LA CEPAL 95. AGOSTO 2008

\section{La nueva pobreza urbana: dinámica global, regional y argentina en las últimas dos décadas}

\author{
Gabriel Kessler y Maria Mercedes Di Virgilio
}

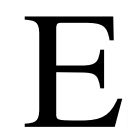

artículo analiza distintas dimensiones de la "nueva pobreza" en las décadas de 1980 y 1990. Presenta en primer lugar las variadas definiciones de dicha categoría en Europa, Estados Unidos y distintos países de América Latina. Se centra luego en Argentina, haciendo referencia al proceso de pauperización sufrido por parte de la clase media de ese país en diversos momentos entre mediados de los años 1970 hasta la crisis del 2001. En una constante comparación con la pobreza estructural, de más larga data, el artículo caracteriza las particularidades de la experiencia de empobrecimiento, las estrategias adaptativas del grupo mediante la utilización del capital cultural y social, así como la erosión de su identidad social y la dimensión urbana de la pauperización. El trabajo concluye con las transformaciones acaecidas en el grupo desde su inicial caracterización hasta el presente y los problemas específicos que plantea a las políticas públicas. 


\section{I}

\section{Introducción}

Una de las consecuencias más inesperadas del gran peso econonómico y sociocultural que los sectores medios han tenido en Argentina fue la de dar origen a un tipo de pobreza con rasgos particulares, una vez iniciado el intenso proceso de empobrecimiento sufrido por la sociedad de dicho país. Baste decir que entre 1980 y 1990 los trabajadores en su conjunto perdieron alrededor de un $40 \%$ del valor de sus ingresos, y luego de cierta recuperación en 1991 debida a la estabilidad, volvieron a perder alrededor del 20\% entre 1998 y 2001, con importantes oscilaciones hasta hoy. ${ }^{1}$ La profundidad y persistencia de la crisis iniciada a mediados de la década de 1970 hicieron que centenares de miles de familias de clase media y de pobres de vieja data, que en el pasado habían podido escapar de la miseria, vieran reducirse sus ingresos hasta caer debajo de la "línea de pobreza". En el Gran Buenos Aires, habitado en la actualidad por unos 13 millones de personas, la pobreza creció en un $67 \%$ durante los años 1980. Entre los pobres destacaba un grupo, el de los ex integrantes de las clases medias que se pauperizaban: el de los nuevos pobres. A ellos habría que agregar aquellos que las estadísticas oficiales no consideraban pobres, pero cuyos ingresos habían sufrido una caída muy significativa, obligándolos a un cambio total de sus estilos de vida. Desde entonces, el fenómeno de la nueva pobreza se instaló en la sociedad argentina. En la década de 1980, la nueva pobreza fue causada en gran medida por el impacto de sucesivos procesos inflacionarios e hiperinflacionarios sobre el ingreso, mientras que en los años 1990 se debió sobre todo a los elevados índices de desempleo registrados a partir de los primeros años de la década. En el cambio de siglo el fenómeno se profundizó y con la crisis de la convertibilidad (2001-2002) la pobreza llegó a afectar a más del $40 \%$ de la población del país.

La pauperización de los sectores medios marcó un punto de no retorno, el fin de un determinado tipo de sociedad. Hasta entonces la sociedad argentina había sido relativamente integrada, al menos en comparación con la mayoría de las latinoamericanas; en ella había surgido una

$\square$ Los autores agradecen las sugerencias del evaluador anónimo del artículo.

${ }^{1}$ Los índices más elevados se registraron a fines de $1989(38,2 \%)$ y en octubre del $2002(42,3 \%)$ y entre esos años los registros siempre superaron los dos dígitos. importante clase media, como resultado de un proceso de movilidad social ascendente ${ }^{2}$ cuya continuidad no se ponía en duda. La nueva pobreza cambió la imagen que la sociedad argentina tenía de sí misma y, en el campo de los estudios sobre la pobreza, obligó a replantear la visión de un sector de la población considerado hasta entonces mayoritariamente homogéneo. También trajo nuevos desafíos a las políticas sociales, al verse afectada una población con necesidades, ubicación geográfica y parámetros culturales distintos a los de la pobreza tradicional y para los que no había programas específicos.

Más allá de sus fronteras, el caso de Argentina puede ser de utilidad para reflexionar sobre otras sociedades de la región. Al fin de cuentas, el proceso de concentración de ingresos que se dio en América Latina en los años 1990 ocurrió en gran medida a expensas de los estratos de ingresos intermedios (Hoffman y Centeno, 2003). Y si bien el cariz que puede adquirir el empobrecimiento depende de factores internos, de un modo u otro los sectores medios de los distintos países han ido sufriendo un proceso de pauperización, tema aún poco presente en las publicaciones académicas y en las agendas públicas nacionales. No sucedió así en los países del centro, donde de modos diversos entre sí y también diferentes del caso argentino, el concepto fue utilizado a partir de los años 1980.

Hoy, transcurridas dos décadas desde la acuñación del término, este artículo tiene por objeto examinar los estudios sobre el tema y describir las diversas dimensiones del empobrecimiento. En él presentamos ante todo los estudios sobre la nueva pobreza en distintos contextos regionales, en particular Europa occidental, Europa oriental y los Estados Unidos. Pasamos luego a las investigaciones realizadas en América Latina. Y, por último, analizamos el caso argentino, haciendo hincapié en nuestros estudios sobre las experiencias iniciales de pauperización en décadas pasadas y los cambios que se han producido desde entonces.

\footnotetext{
${ }^{2}$ El imaginario de la movilidad podía condecirse con procesos realmente acaecidos. Un estudio clásico sobre movilidad intergeneracional basado en datos de 1960 (Germani, 1963), muestra que en el Gran Buenos Aires el $36,5 \%$ de los entrevistados hijos de obreros conocieron en una generación una movilidad ascendente hacia puestos de clase media y clase alta. Por su parte, el 77\% de los entrevistados cuyos padres pertenecían a la categoría ocupacional más baja —obreros no calificados— había ascendido, ya sea al nivel de obrero calificado o a puestos de sectores medios.
} 


\section{II}

\section{La nueva pobreza en el contexto internacional}

Los conceptos de "nueva pobreza" y "nuevo pobre" se presentan en la teoría sociológica como nociones polisémicas, por ser el resultado de un mismo interrogante desde distintos puntos de vista: las características particulares del nuevo grupo empobrecido, en comparación con aquellas de la pobreza que había existido hasta entonces en cada país. En Europa occidental estos conceptos se adoptaron a fines de los años 1980, en los albores del interés por la "nueva cuestión social". ${ }^{3} \mathrm{El}$ principal punto de inflexión fue el inusitado incremento del desempleo y de la pobreza: la desocupación en la que era entonces la Comunidad Europea pasó de un $2,4 \%$ en 1973 a un $11 \%$ en 1989, produciéndose una "desestabilización de los estables" (Castel, 1995) que afectó a grupos sociales cuya integración parecía hasta entonces asegurada. No solo se incrementó el número de desocupados sino que aumentó también la duración media del desempleo, factores que dieron origen a una masa creciente de desempleados por plazos largos. Como corolario, hubo un incremento de la pobreza que señaló el fin del período de posguerra conocido como “los gloriosos treinta años”. Según O'Higgins y Jenkins (1989), que estudiaron la pobreza relativa en 12 países europeos, entre 1975 y 1980 el número de pobres pasó de 3,6 millones de personas a 39,5 millones y siguió creciendo hasta llegar a 43,9 millones en 1985.

En forma inmediata subió el número de personas dependientes de los servicios sociales y de otras formas de asistencia. Así, en países de la Comunidad Europea se duplicaron los beneficiarios de ayudas sociales en las décadas de 1970 y de 1980. En tal situación, las medidas sociales de corte tradicional resultaron insuficientes. La nueva pobreza obligó a reconsiderar los dos pilares sobre los que se habían asentado los Estados de bienestar en Europa occidental en la posguerra. Esos pilares eran, por

\footnotetext{
${ }^{3}$ La primera publicación en que se encuentra el término es alemana, data de 1984 y su título es, justamente, los nuevos pobres, Die Neue Armut (Balsen, Nakielski y otros, 1984). Sin embargo, ya había aparecido en 1979 un trabajo sobre el proceso de pauperización en Italia (Carbonaro, 1979). En 1988, un informe de la entonces Comunidad Económica Europea utilizó la noción de nueva pobreza al alertar sobre las posibles consecuencias sociales de la creación de un mercado único, señalando que su implementación podría tener efectos muy negativos para ciertas áreas y categorías de personas y generar exclusión social, marginalización y la ...aparición de nuevas formas de pobreza (Comunidad Económica Europea, 1988, pág. 23). El destacado en negrita es nuestro.
}

un lado, los seguros de desempleo destinados a encarar la desocupación friccional, que se volvieron insuficientes para cubrir una población excluida por largo tiempo del mercado de trabajo y que había agotado sus reservas de contribuciones a la seguridad social. Por el otro, las medidas asistenciales focalizadas en quienes eran considerados no aptos para el trabajo, lo que tampoco coincidía con el perfil de los nuevos demandantes. Se estuvo en consecuencia ante un cambio cualitativo de la población asistida: a la par que disminuían los ancianos y las familias numerosas, se incrementaban las personas en plena edad activa, los hogares monoparentales y las personas solas. Esta mutación de perfiles se reflejó en las demandas: aumentaron los problemas de endeudamiento excesivo y los de alquileres, deudas y servicios impagos, problemas propios de una población cuya caída trastocaba su patrón de gastos habituales y de compromisos financieros a largo plazo. Por último, se asociaron al empobrecimiento fenómenos novedosos, entre otros, nuevas formas de economía informal, poblaciones sin techo y más delincuencia.

En estas circunstancias, la nueva categoría suscitó interés mediático, académico y político en diversos países. ${ }^{4}$ La nueva pobreza provocó una fuerte preocupación en las clases medias por su propia suerte: la miseria ya no era de los otros, del "cuarto mundo" como se la llamaba hasta entonces. El derrotero de individuos con los que se tenía en común el origen social, las competencias profesionales y el perfil sociocultural tornaba repentinamente visible la vulnerabilidad de la propia situación. Al fin de cuentas, el desplazamiento de individuos indudablemente integrados parecía poner en duda dos creencias básicas y articuladas: la vigencia de una organización meritocrática de la sociedad - es decir, la distribución de premios y castigos en virtud de los méritos personales-y el ideal de progreso social, en tanto creencia de que existen mecanismos para controlar el porvenir de una sociedad desarrollada, dominar sus turbulencias y conducirla hacia formas de equilibrio cada vez más articuladas (Castel, 1995, p. 387).

Con todo, la emergencia de estos conceptos no careció de oposición en el campo académico. Por un lado, se

\footnotetext{
${ }^{4}$ Por ejemplo, en Barthe (1987), Marklund (1990), Mingione y Zajczyk (1992), Neef (1992), Paugam (1991 y 1993) y Room (1989).
} 
sostuvo que la focalización en la nueva pobreza desviaba la atención de los pobres tradicionales, cuya situación relativa era peor. Se argumentó además que el adjetivo "nueva" sugería erróneamente que la pobreza era un fenómeno de reciente data (Kelly, 1984). Algunos cientistas sociales preferían otras nociones emergentes, como "exclusión social" y "desafiliación" en el caso francés, mientras que en Gran Bretaña Gaffikin y Morrisey (1992) encontraban que "nueva desigualdad" era una expresión más adecuada para caracterizar el aumento de las diferencias de ingreso entre distintos estratos de la sociedad.

De hecho, en los últimos años declinó el interés europeo en la noción de nueva pobreza y el concepto que logró instalarse con mayor relevancia intelectual y sobre todo política fue el de exclusión social. En el nuevo milenio la movilidad descendente dejó de ser una novedad; actualmente muchas investigaciones dan por sentado que las nuevas generaciones vivirán peor que las precedentes. Así, por ejemplo, McDowell (2002) reflexiona en el Reino Unido sobre la definición de la masculinidad ante las improbabilidades de que los hombres puedan cumplir con el rol de proveedores para el que han sido socializados, mientras que en los Países Bajos autores como De Regt y Weenik (2000) ahondan en las estrategias educativas de los padres holandeses para evitar la movilidad descendente de sus hijos. También en Europa occidental una parte minoritaria de los estudios ha relacionado la noción de nueva pobreza con las corrientes migratorias emergentes. Si se la vincula a las más recientes migraciones desde África, Asia y América Latina, esa noción adquiere nuevo significado a partir de conflictos territoriales, económicos, religiosos y étnicos asociados a las tensiones que genera la incorporación de las "nuevas poblaciones" en el seno de las sociedades europeas (Molina, 2001; Søholt, 2001; Bolt y van Kempen, 2003). Se destaca así la acumulación de desventajas que encaran estos nuevos migrantes, a cuyas precarias condiciones de vida y de trabajo se suman con frecuencia la discriminación, la soledad, el aislamiento y el desarraigo.

En Europa del este, la abrupta caída de los regímenes socialistas generó un fuerte interés por la nueva pobreza a comienzos de los años 1990, tras la repentina pauperización producida por los cambios político-económicos. Una causa fundamental de ella fue el aumento de la desocupación por el desprendimiento de mano de obra excedente en todos los sectores de la economía. Asimismo, pronto los salarios se revelaron insuficientes para afrontar los costos de una economía de mercado. La mercantilización de bienes y servicios que antes se ofrecían a precios muy bajos o gratuitamente por el Estado, tuvo un demoledor impacto en los apretados presupuestos familiares. El empobrecimiento en los primeros años pareció ser dramático, incluso en los países que establecieron con relativa rapidez el seguro de desempleo, como Hungría, la República Checa y Polonia (Tortosa, 1992). Más recientemente, una segunda generación de estudios se llevó a cabo en contextos ya estabilizados. Algunos comparan las distintas formas de transición hacia el mercado de los ex países socialistas y los impactos a mediano plazo de cada una de ellas en la desigualdad y en la movilidad descendente (Titma y Murakas, 2004). Otros muestran una preocupación creciente por el empobrecimiento de minorías étnicas, en particular la de gitanos o rom en Bulgaria, Hungría y Rumania (Ladanyi y Szelenyi, 2002); se habla de una "nueva infraclase étnica" (Mitev, 2001) que sufre discriminación y cuyo bajo capital humano y estilo de vida migrante dificultan la inserción. Son también de interés los estudios sobre el derrotero de las ex elites políticas, vinculado a la movilidad descendente, que no llega a la pobreza. Kryshtanovkaia (2005) rastrea los procesos de desincorporación de elites en Rusia, señalando la variedad de formas - algunas exitosas, otras no- de reconversión del antiguo capital político en capital económico. Asia no es ajena al interés por las clases medias: proyectos sobre las clases medias de Asia oriental y sudoriental (East Asia Middle Class Project y Southeast Asia Middle Class Project) analizan su devenir en distintos países, aunque el signo de la movilidad es ascendente más que descendente (So, 2004). Un caso interesante es la emergencia de una categoría de "nuevo pobre" en Uzbekistán, cuya expresión política es una nueva izquierda populista que articula elementos del pasado soviético con principios islamistas (Ilkhamov, 2001).

En los Estados Unidos dicha categoría se ha utilizado para examinar tres problemáticas que preocupan a la sociología de ese país. Un primer grupo de trabajos que estudia la "clase media declinante" se inscribe en el interés clásico por la movilidad social, aunque en dirección opuesta, ya que la mayoría de los estudios sobre este tema se centra en la movilidad ascendente. En efecto, desde mediados de los años 1980 la reestructuración organizacional vinculada a la "nueva economía" redujo puestos intermedios, causando el desplazamiento de cuadros intermedios y un empobrecimiento no visto desde la crisis de los años $1920 .{ }^{5}$ En ese marco se asistió

\footnotetext{
${ }^{5}$ Véase, por ejemplo, Blackburn y Bloom (1985), McMahon y Tschetter (1986), Newman (1989 y 1993), Rosenthal (1985) y Strobel (1993).
} 
también al fin del proceso de expansión, iniciado en la década de 1960, de una clase media afroamericana cuya movilidad descendente afecta al conjunto del grupo étnico (Attewell, Lavin y otros, 2004).

Una segunda vertiente de estudios sobre la "nueva pobreza urbana" se aleja de las clases medias y examina la situación de las clases obreras desplazadas por la reestructuración industrial en las urbes del centro y este de los Estados Unidos; indaga en particular en la suerte de los sectores menos calificados y más segregados desde el punto de vista social y espacial — los afroamericanos y más recientemente los latinos-, retomando el debate sobre la infraclase (underclass) iniciado en los años 1960. Las causas de la permanencia de esta infraclase fueron un fundamental eje de controversia entre académicos progresistas con posturas más estructuralistas, como Devine y Wright (1993) y Wilson (1987), y académicos neoconservadores como Auletta (1982), Mead (1986) y Murray (1984). Estos últimos las atribuyeron a "efectos perversos" de los programas sociales, que desincentivaban el trabajo y la responsabilidad individual, y se erigieron durante el gobierno de Reagan en exitosos ideólogos de la reducción de tales programas.

Un tercer grupo de trabajos se ubica en la intersección entre los estudios migratorios y los de movilidad social. El foco de interés es el empobrecimiento de la "nueva segunda generación", en particular la de hijos de inmigrantes latinos. Esa movilidad descendente intergeneracional cuestiona la clásica teoría de la asimilación, que supone un ascenso social de la segunda generación al aunar ímpetu emprendedor con un capital humano mayor que el de sus padres. Portes y Zhou
(1993) sostienen que existe un proceso de "asimilación segmentada", por cuanto los nuevos factores estructurales y de capital humano obstacularizarían una inserción exitosa, transformando a esa segunda generación en una nueva infraclase multicolor (new rainbow underclass), fuertemente racializada. La hipótesis ha sido apoyada por algunos trabajos, como el de Kazemipur y Halli (2001) en Canadá, pero cuestionada por otros. Waldinger y Feliciano (2004), tras analizar una cohorte de hijos de inmigrantes mexicanos, señalan que más que una infraclase lo que hay es una movilidad ascendente de tramos cortos, que lleva a la nueva generación a insertarse en las franjas más bajas de la clase obrera. Una situación particular es la estudiada por Sabogal (2005): dicha autora, centrándose en la migración de profesionales peruanos a los Estados Unidos, describe el proceso de movilidad descendente que los afecta al pasar al estatus de inmigrantes ilegales o no poder validar sus credenciales profesionales. Por último, Fothergill (2003) investiga las consecuencias de una forma de movilidad descendente poco estudiada, aquella causada por catástrofes naturales.

En resumen, al caracterizar fenómenos novedosos visibles a partir de la década de 1980, la noción de nueva pobreza apunta sobre todo a la emergencia de grupos de población afectados por una fuerte movilidad descendente y formas de pobreza diferentes a las conocidas en cada contexto, lo que pone en tela de juicio visiones más bien homogéneas de dichos grupos y plantea la necesidad de diseñar políticas públicas para una población con carencias que es cualitativamente distinta de la población pobre tradicional.

\section{III}

\section{La nueva pobreza en América Latina}

Quizás porque la pobreza tradicional persiste y el peso de los sectores medios se ha considerado históricamente como reducido, la noción de nueva pobreza no ocupa en América Latina el lugar central que ha tenido en otras latitudes. Tampoco en los innumerables estudios sobre la pobreza de los organismos internacionales se registran muchas referencias a ella. Sin embargo, y todavía con escaso protagonismo, la situación de las vulnerables clases medias locales ha estado presente en el debate nacional. En efecto, esas clases medias han sido afectadas de uno u otro modo en distintos países por la crisis de la deuda en la década de 1980 y más tarde por los programas de ajuste estructural, los procesos de concentración de los ingresos, el encarecimiento de los servicios privados y pérdida de calidad de los servicios públicos, así como por los cambios en el mercado de trabajo en los años 1990.

En Chile, en uno de los primeros trabajos publicados en el país sobre el tema, Lomnitz y Melnick (1991) examinaron la situación de los docentes bajo el régimen de Pinochet. Las reformas en el sistema de enseñanza nacional y la interdicción de la acción sindical habían provocado una pérdida de poder económico y social de los maestros y, en particular, habían debilitado las bases 
materiales del "compadrazgo". Este sistema informal de intercambio de favores en el seno de una clase media ocupante de los puestos públicos constituía una red de reciprocidad ampliada que le permitía a sus integrantes usufructuar de las mejores prestaciones en salud y educación y aprovechar las oportunidades laborales en el Estado. Casi dos décadas más tarde, la preocupación por la pauperización volvió a Chile pero de un modo distinto. Según Ugalde y Prieto (2001), luego de haberse acuñado la idea de "clase media emergente" — caracterizada por su movilidad ascendente a puestos calificados en un sector de servicios en expansión-, los límites del modelo de desarrollo y el freno al descenso de la pobreza hicieron resurgir el tema. Ya en el año 2000 se observaba que los sectores de menores recursos eran los más afectados por la pérdida de empleo y por la depreciación de sus ingresos. El aumento de las tasas de desempleo abierto en el país y en la Región Metropolitana a partir de 1998 tuvieron "como contracara la reproducción de altos niveles de desigualdad" (Sabatini y Wormald, 2005, p. 233). El empobrecimiento de sectores medios bajos y una clase media emergente que asciende son dos aspectos de la particular configuración de la desigualdad que Torche (2005) constató en Chile. Su estudio muestra que la estructura social chilena exhibe una importante movilidad ocupacional, una alta concentración del ingreso en los deciles superiores y una escasa diferenciación de ellos entre los sectores bajos y medios bajos, por lo cual estos últimos son estructuralmente muy vulnerables: cualquier precarización de las condiciones de trabajo o movilidad ocupacional ligeramente descendente puede implicar la caída en la pobreza.

A la vez, en un entorno en que el mercado de trabajo privilegia las altas calificaciones, ha surgido un nuevo fenómeno de "pobreza dura" que afecta a personas y hogares carentes de los recursos y oportunidades mínimos para superar esa condición por sus propios medios. Favorece el desarrollo de la pobreza dura el modelo de provisión mixta y la mercantilización de los servicios sociales según el nivel socioeconómico de los hogares (Wormald, Cereceda y Ugalde, 2002); esta situación resulta especialmente crítica en el acceso a servicios como los de educación (Sabatini y Wormald, 2005). Por su parte, el trabajo de Torche y Wormald (2004, p. 70) pone de manifiesto que la inversión en educación efectuada por los hogares chilenos no tiene igual rentabilidad en distintos estratos sociales. Es menos rentable para los segmentos de clase media baja, en el marco de un mercado de trabajo que incentiva la reproducción de una estructura salarial relativamente polarizada, y es indiferenciada en sus segmentos in- termedios. Espinoza (2006) completa el cuadro con el análisis de los datos de una encuesta sobre movilidad ocupacional. ${ }^{6} \mathrm{Su}$ estudio pone en evidencia que si bien para los santiaguinos el acceso a las ocupaciones más calificadas ha estado abierto en las últimas décadas, los efectos de exclusión siguen afectando significativamente a los sectores de clase media baja. En una estructura de movilidad ocupacional de tramos cortos como la chilena, el acceso a los puestos de trabajo calificados continúa vedado a los miembros de familias modestas de clase media. La nueva pobreza también fue pensada en Chile en relación con el lugar de residencia. Tironi (2003) señala que la vivienda crea en Chile nuevas precariedades, debidas básicamente a cambios en la configuración del capital social causados por la destrucción de lazos comunitarios establecidos en el hábitat de origen.

En México la evolución de la pobreza exhibe también particularidades. En los años 1990 las tasas de desempleo fueron bajas; sin embargo, los bajos niveles de desempleo no impidieron una marcada reducción de los salarios ni el crecimiento del sector informal (Bayón, 2006). Las reducidas tasas de desempleo abierto tuvieron como contrapartida una alta ocupación en el sector informal de la economía, salarios bajos y escasa participación salarial en el producto interno bruto (López, 1999). La información disponible para la Ciudad de México sugiere además que se está registrando una polarización de los ingresos. De la población trabajadora en general, solo el personal directivo y los trabajadores en servicios semiprofesionales mejoraron considerablemente sus ingresos reales a lo largo de la década de 1990: hacia fines de esa década sus ingresos eran $25 \%$ más altos que en el año 1990. Los restantes grupos ocupacionales, algunos de ellos pertenecientes a sectores medios - empleados administrativos, trabajadores por cuenta propia, trabajadores manuales calificados, semicalificados y sin calificación y trabajadores manuales en servicios de baja calificación- sufrieron el deterioro de su ingreso real, que a fines de la década era inferior al de 1990.

En su análisis de la movilidad social intergeneracional en áreas urbanas de México, los autores Cortés y Escobar Latapí (2005) señalan que durante el período de reestructuración económica (1988-1994) disminuyeron las posibilidades de movilidad en todos los estratos. No obstante, el efecto fue mucho más marcado en las

\footnotetext{
${ }^{6}$ Los datos que analiza Espinoza (2006) provienen de una encuesta realizada en Montevideo, Buenos Aires y Santiago en septiembre del 2000, en el marco del Proyecto Fondecyt 1990818. La encuesta permitió reconstruir las historias laborales de trabajadoras y trabajadores que en ese momento tenían entre 35 y 50 años de edad.
} 
clases de menores ingresos: trabajadores no calificados de la industria, trabajadores informales de los servicios, ejidatarios, pequeños propietarios rurales y jornaleros. Bajo el nuevo modelo económico creció la desigualdad de oportunidades existente entre los integrantes de las clases más bajas y los originarios de la clase más alta: profesionales, funcionarios y empleadores de más de cinco trabajadores. Así, no solo se intensificó la desigualdad, sino que el sistema de movilidad ocupacional se tornó más rígido. Las oportunidades son también menores para las generaciones más jóvenes. Parrado (2005) muestra que para los nuevos trabajadores el hecho de tener un alto nivel educativo no es una barrera protectora contra la movilidad descendente, cuestionando así la anclada creencia en la educación como vía para la movilidad.

Además de Argentina, cuya situación se analiza más adelante en la sección IV, hay otros dos países latinoamericanos donde el tema del empobrecimiento de los sectores medios ha suscitado más atención: Uruguay y Costa Rica. Uruguay ha mantenido un patrón de desigualdad mucho menor que el de la mayoría de los países de la región o que el promedio regional, aunque ya a fines de los años 1980 se alertaba sobre la emergencia de nuevos pobres provenientes de las clases medias (Kaztman, 1989). Con posterioridad, en trabajos recientes ha emergido la preocupación por las causas y consecuencias del aumento de la desigualdad. Los procesos de empobrecimiento se vincularon al comportamiento del mercado de trabajo, en particular al aumento de las tasas de desempleo abierto y empleo informal y a la reducción relativa del empleo público, que acortaba las diferencias salariales (Kaztman, Filgueira y otros, 2005). Asimismo, entre los dependientes de remuneraciones del trabajo, crecieron las diferencias de ingreso entre hogares con jefes de diferente nivel educativo y tendió a ampliarse la distancia de los miembros de hogares con al menos un desocupado (Bucheli y Furtado, 2004). De este modo, el empobrecimiento estuvo centrado en el descenso de sectores de clase media baja, una caída de "tramo corto" similar a la que en Argentina afectó a una parte de la clase media menos asentada.

El caso de Costa Rica, por su parte, tiene connotaciones similares a las del caso argentino. No por casualidad este país, cuya identificación social en la región también se basa en la presencia de una fuerte clase media, ante cada episodio de crisis pareciera replantearse una eventual desaparición de la clase media como una manera de plantearse un interrogante más general sobre cambios en toda la estructura social. El trabajo de Vega Martínez (1999) muestra que si bien el peso cuantitativo de la clase media local se mantiene estable, sus niveles de vida han sido afectados. El efecto de la retracción del Estado como empleador, así como el mayor gasto de los hogares medios en prestaciones de salud y educación privadas ante la pérdida de calidad de los servicios públicos, hablan de una clase media muy articulada con el Estado. De este modo, concluye la autora citada, la clase media costarricense entra en crisis cuando el Estado entra en crisis y, como la de Uruguay, se ve afectada por la desestabilización de su matriz igualitaria (Montero y Barahona, 2003). También hay evidencias de procesos de empobrecimiento en Venezuela, con un importante aumento del desempleo y la pobreza, y en Cuba, según Hoffman y Centeno (2003), por la entrada de capitales extranjeros y la privatización de sectores de la economía, que habrían creado un "dollar apartheid".

Por último, Brasil también aborda el tema de sus clases medias, pero no tanto desde el ángulo de la nueva pobreza, sino más bien atendiendo a la imagen de una clase media amenazada en distintos frentes. En primer lugar, por la inseguridad urbana: la investigación de Caldeira (1996) describe una clase media que levanta murallas fortificadas en sus enclaves privados. Otros trabajos muestran fracciones más tradicionales de los sectores medios amenazados por los cambios en la economía y en el mundo del trabajo. O'Dougherty (1999) encuentra una clase media que teme perder sus niveles de consumo, pero que a diferencia de su par argentina, que adjudica al modelo neoliberal la causa de sus males, cree que las reformas gubernamentales y económicas neoliberales permitirían retornar al mundo del consumo de las clases medias, del que teme ser excluida. Trabajos como los de Valladares, Pétreceille y otros (2005) cuestionan la idea de "dos Brasiles", uno marginado y otro formal y moderno; postulan en cambio la de un "Brasil complejo", en gran medida por el peso creciente de las clases medias urbanas. En las últimas décadas, la llamada "democratización del consumo" de bienes durables entre familias brasileñas de bajos ingresos añade a esta complejidad. Mota Guedes y Vierra Oliveira (2006, p. 1 y ss.), a partir del análisis de encuestas sobre consumos de hogares, señalan que "los brasileños de bajos ingresos comenzaron a comprar bienes y servicios cuyo consumo estaba tradicionalmente limitado a las clases media y alta", como refrigeradores dúplex, teléfonos celulares, automóviles, pasajes aéreos, paquetes turísticos y tarjetas de crédito. El acceso a ellos se vio facilitado por el control de la inflación, la expansión del crédito y la caída de los costos de bienes y tecnologías. En este marco cabe preguntarse si la democratización del consumo constituye un buen indicador de la redefinición de las fronteras entre 
clases sociales o si más bien en ese mismo proceso se construyen otras señales de diferenciación, como por ejemplo los lugares donde se consume, la calidad de los bienes y el acceso a servicios. A este interrogante se suman otros, que se plantean también en el trabajo citado, como la sostenibilidad del endeudamiento de las familias de bajos ingresos y los insuficientes niveles de inversión en educación.

\section{IV}

\section{El empobrecimiento en Argentina}

\section{Las causas del empobrecimiento}

Entrando ya de lleno al caso argentino, el empobrecimiento de los sectores medios es el resultado de una serie de factores que se han ido sumando a lo largo de las dos últimas décadas. Si se sintetizara el derrotero de los nuevos pobres, habría que mencionar ante todo la depreciación de los ingresos de las categorías socioprofesionales intermedias tras la instauración del gobierno militar en 1976. En efecto, la nueva pobreza fue en sus comienzos el resultado de una contracción salarial más que de una pérdida de lugar en el mundo del trabajo, como en Europa occidental. Una segunda fase de empobrecimiento comenzó en los años 1990 con el aumento del desempleo y, sobre todo a partir de 1995, por una distribución del ingreso desfavorable a los trabajadores menos calificados, que afectó también a los estratos medios bajos. Además, la creciente inestabilidad de los puestos de trabajo, que perjudicó primero a los menos calificados y se extendió luego a los más calificados, fue un nuevo factor de empobrecimiento.

Cabe examinar un poco más en detalle los distintos factores mencionados. El empobrecimiento de los años 1980 se produjo por la depreciación del salario y la pérdida de los beneficios directos e indirectos ligados a los puestos de trabajo, aunque la inflación y la baja productividad de los distintos sectores posibilitaba que la tasa de desempleo se mantuviera relativamente baja. La hiperinflación de 1989 marcó un punto de inflexión a partir del cual la historia del empobrecimiento se aceleró en asociación con el aumento del desempleo. A modo indicativo, diremos que en el Gran Buenos Aires -el distrito con más población de Argentina-, el desempleo subió de 6\% a 17,9\% entre 1991 y el 2000. La Ley de convertibilidad (Plan Cavallo) aprobada en 1991 favoreció la estabilidad macroeconómica y el crecimiento, pero no fue suficiente ni para quebrar la tendencia a una creciente desigualdad de los ingresos entre los hogares ni para resolver los problemas del mercado de trabajo (Altimir y Beccaria, 1999). La mejoría temporal experimentada durante los primeros años de la década de 1990 revirtió en parte la tendencia al deterioro salarial, pero no bastó para recuperar los mejores niveles de los años 1980. A partir de 1994 los ingresos tuvieron un nuevo punto de inflexión, pues comenzó a acentuarse la desigualdad al disminuir los ingresos de los menos calificados: en mayo de 1999 una persona del decil más rico de la población ganaba 25 veces más que una del decil más pobre. Dos años antes la diferencia era de 23 veces, a principios de los años 1990 de 15 veces y a principios de los años 1980 de ocho veces (CELS, 2001).

La crisis del mercado laboral y la creciente desigualdad entre los ingresos de los hogares impactaron fuertemente en las condiciones de vida de algunos sectores de clase media y se plasmaron en forma paulatina en la emergencia de una nueva pobreza vinculada a la falta de recursos monetarios. Los pobres por insuficiencia de ingresos representaban el 3,2\% de la población en 1980 (Minujin, 1992). A fines de la década de 1990 , el $26,7 \%$ de las personas - reunido en el $18,9 \%$ de los hogares- no percibía ingresos suficientes para acceder a la canasta básica de bienes y servicios (INDEC, 2003). Más allá de la mejoría temporal que experimentaron ciertos grupos en los inicios de los años 1990, en función del proceso de estabilización económica, la pobreza por insuficiencia de ingresos se consolidó como tendencia estructural.

A fines del 2001, el mercado laboral argentino presentaba una elevada desocupación abierta y una mayor precarización e inestabilidad de las ocupaciones. Esto último como consecuencia del peso creciente de los puestos asalariados no registrados (empleo informal) y del menor grado de estructuración de las ocupaciones independientes. Tal como afirman Beccaria y Mauricio (2005), ambos fenómenos se influían mutuamente: por un lado, el crecimiento de la precariedad se explicaba por la existencia de un amplio conjunto de personas que, ante la falta de un empleo pleno y estable, estaban 
dispuestas a aceptar puestos de trabajo de baja calidad. Por el otro, la mayor presencia de puestos inestables hacía que aumentara la tasa de ingreso al desempleo, el que se caracterizaba por episodios relativamente cortos. Un amplio sector de la fuerza de trabajo transitaba regularmente entre empleos precarios, de corta duración, y episodios de desocupación también breves.

Hacia fines del 2002 comenzaron a mejorar las condiciones del mercado de trabajo y, por ende, a disminuir los niveles de pobreza. A la par del crecimiento económico, los niveles de ocupación aumentaron con rapidez y la tasa de desocupación retrocedió sin pausa. Los salarios, en cambio, se recuperaron con lentitud y aún hoy exhiben en términos reales niveles medios inferiores a los del 2001. Cabe preguntarse entonces cómo ha impactado esta situación en los distintos grupos de trabajadores. ¿Ha disminuido la brecha entre quienes se encuentran en los extremos de la pirámide salarial? Al comparar los trabajadores con remuneraciones extremas, se observa que el ingreso laboral medio del $10 \%$ con remuneraciones más altas es 30 veces mayor que el del $10 \%$ con remuneraciones más bajas. En los años recientes, el nivel de actividad económica ha crecido al 9\% anual y la cantidad de puestos de trabajo ha aumentado aproximadamente en dos millones y medio. Los ingresos laborales reales, sin embargo, no han seguido el ritmo de esta recuperación económica ni del aumento del empleo. ${ }^{7}$ Antes bien, continúan en niveles inferiores a los del 2001 y la brecha entre los salarios extremos ha vuelto a crecer desde fines del 2004. El grado de desigualdad en las remuneraciones - que muestra una tendencia ascendente desde mediados de la década de 1970 - ha disminuido, pero esta tendencia es restringida. En definitiva, la desigualdad en sí no solo continúa siendo muy elevada sino que no ha decrecido sustancialmente respecto de los altos niveles de fines de la década de 1990. Ahora bien ¿cómo ha influido esto en los nuevos pobres? Es posible que aquellos que estaban desocupados, contaban con más capital educativo y eran más jóvenes hayan tenido mayores posibilidades de reinsertarse en el mercado de trabajo. Cabe pensar

\footnotetext{
${ }^{7}$ Los efectos de la inflación con la que convive Argentina desde que se declaró el fin de la Convertibilidad también se hacen sentir en el salario, disminuyendo su capacidad adquisitiva. A modo de ejemplo puede citarse que en abril del 2005 el índice de precios al consumidor (IPC) se incrementó en un 4\%, mientras que los precios de los índices que miden la indigencia y la pobreza — la canasta básica de alimentos (CBA) y la canasta básica total (СВT) — subieron 5,8\% y 4,4\%, respectivamente. Por lo tanto, los hogares necesitaron más recursos para superar los umbrales de indigencia y de pobreza determinados por esas canastas.
}

también que posiblemente los que ocupaban puestos de bajas remuneraciones hayan conocido algunas mejoras en sus ingresos.

\section{La experiencia de pauperización}

El empobrecimiento sin pérdida de posición laboral constituye una experiencia particular, distinta del desempleo o la pobreza estructural. Vale la pena entonces detenerse en sus principales características. Nuestros trabajos sobre la experiencia de la pauperización (Kessler, 1998 y 2000; Kessler y Di Virgilio, 2005; Minujin y Kessler, 1995) ${ }^{8}$ y los de otros autores (Minujin 1992; Feijoó, 2001) fueron mostrando las aristas de este proceso que caracterizó a la nueva pobreza argentina en sus comienzos. Un primer rasgo importante es que los nuevos pobres constituyen un estrato híbrido: están próximos a los sectores medios en variables ligadas a aspectos económico-culturales que actúan en el largo plazo, como el nivel educativo y la composición de la familia - menos numerosa que la de los pobres estructurales-, pero se asemejan a los pobres estructurales en el nivel de ingresos, el subempleo y la ausencia de cobertura social, es decir, en variables de corto plazo, producto de la crisis. Los datos indican también que la nueva pobreza se caracteriza por la polarización y la heterogeneidad. Las estadísticas señalan que los ingresos de todas las categorías ocupacionales cayeron de manera sensible durante los años 1980, al tiempo que en cada categoría crecía la distancia entre los que percibían los ingresos más elevados y aquellos más cercanos al piso salarial. La nueva pobreza surgió así como un universo heterogéneo que reunía a los "perdedores" de cada categoría profesional. La heterogeneidad cuantitativa tenía su correlato cualitativo: la diversidad de perfiles socioprofesionales conllevaba trayectorias sociales diferentes en cuanto a las formas de socialización, los orígenes familiares, las carreras educativas y las historias profesionales. En esos derroteros heterogéneos previos a la experiencia de la pobreza, los individuos fueron internalizando expectativas, creencias, pautas de consumo y recursos potenciales, muy divergentes. Así, una vez pauperizados, tal variedad de trayectorias estará en el origen de formas heterogéneas de experimentar la pobreza.

\footnotetext{
${ }^{8}$ Los tres apartados siguientes, a menos que se indique otra cosa, se basan principalmente en las investigaciones señaladas, de carácter cuantitativo y cualitativo, que fueron realizadas en la Ciudad de Buenos Aires, Santa Fe, Tucumán y Presidencia Roque Sáenz Peña durante la década de 1990. Los estudios posteriores, más acotados, se llevaron a cabo en Buenos Aires (Cortés y Kessler, 2004; Kessler, 2008).
} 
La pauperización es un trastocamiento general: todos los aspectos de la organización familiar ligados a lo económico e incluso las prácticas más rutinarias y normalmente menos problemáticas, son sometidos a revisión, modificación y supresiones (Feijoó, 1992). Al fin de cuentas, puede obligar a sacar a un hijo del colegio privado al que fueron sus hermanos mayores, modificar la dieta familiar, restringir el uso del automóvil o los viajes en colectivo, no asistir a una fiesta por falta de ropa adecuada, dejar de lado el club, la computación, la terapia, el fútbol, la música, las revistas, el cine, las vacaciones, la medicina prepaga y parte de la vida social, atrasarse peligrosamente en el pago de impuestos, abandonar el seguro y las cuotas de un crédito ya mitad pagado, adoptar en familia una nueva regulación de las frecuencias de invitaciones a comer en la casa, del régimen de visitas al dentista así como del consumo de luz y teléfono, entre tantas otras medidas.

Esto que hemos llamado una constante coacción al cambio es una de las singularidades del empobrecimiento. Como experiencia, se diferencia de una situación estable en la que las rutinas vigentes tienden a perpetuarse y el tiempo transcurre sin forzar a tomar decisiones en forma constante. Se distingue también de la movilidad ascendente, donde el cambio existe, pero producto de una elección deliberada. En contraposición, la movilidad descendente genera una creciente complejidad en la vida cotidiana de quienes realizan permanentes esfuerzos para estabilizarla; la necesidad de hacerlo es tanto más acuciante porque para los afectados no se trata solo de una alteración de la situación personal, sino también del mundo circundante. En efecto, la dislocación de la cotidianeidad va afectando tramos de sentido sedimentados: ideas, creencias, expectativas, categorías de percepción, hasta entonces dadas por descontado, que no resisten a la dislocación de la cotidianeidad. La pauperización se experimenta como una dislocación personal y como una desorganización del mundo social circundante. Esta doble percepción lleva a que no pueda producirse una "adaptación" en el sentido clásico del término: el acomodamiento a un contexto nuevo definido o definible. Así, es preciso dotar de significado a una situación para la que no se encuentra respuesta ni en las "reservas de experiencias comunes de la sociedad" ${ }^{\prime \prime}$ ni en la propia historia familiar.

\footnotetext{
${ }^{9}$ Se hace referencia al concepto de acervo de conocimiento (stock of knowledge) de Schutz. Dicho autor sostiene que toda interpretación del mundo está basada en una reserva de experiencias previas, ya sea propiamente nuestras o transmitidas por nuestros padres o nuestros maestros; estas experiencias, bajo la forma de 'conocimientos dispo-
}

Lo dicho otorga a la pauperización su carácter excepcional en la historia argentina moderna. El empobrecimiento de una parte importante de la clase media significó un corte abrupto con el modelo generacional y con el modelo histórico-cultural hasta entonces vigente. Ni la socialización familiar, ni la cultura, ni las estrategias más cotidianas habían preparado a esos grupos para el empobrecimiento definitivo, sin retorno, lo que sí hicieron las reservas de experiencias de aquellos estadounidenses que en su infancia habían conocido la Gran Depresión (Elder, 1974). La caída marcaba para los nuevos pobres el fin del proceso de reproducción del sentido de la trayectoria social familiar, signada por la movilidad ascendente de cada generación respecto de la anterior. El empobrecimiento sin posibilidad de recuperación era el fin de ese recorrido, un punto de inflexión que amenazaba amplificarse en el futuro con la temible movilidad descendente de sus hijos. Para nuestros entrevistados, el quiebre del modelo históricocultural y generacional se expresaba en una situación de ilegibilidad general, cuya manifestación más notoria era la dificultad para tipificar el nuevo contexto. Así se explica la aparente irracionalidad de muchas familias que intentaban mantener las pautas de consumo habituales y hasta se endeudaban para hacerlo, suponiendo que lo que las afectaba era otra de las cíclicas crisis nacionales. $\mathrm{Al}$ no estar prevista la situación como posible, no se podía apelar a un repertorio de estrategias internalizadas para solucionarla.

\section{Las estrategias adaptativas: usos del capital social y cultural}

Al visitar los hogares de los nuevos pobres en los años 1990, lo primero que llamaba la atención era una aparente dislocación de las estructuras clásicas de jerarquización de necesidades (Kessler, 1998; Minujin y Kessler, 1995). En efecto, en el esfuerzo por "detener la caída" había quienes, aun cuando carecían de cobertura de salud, mantenían un régimen de vacaciones anuales en la costa.

nibles', funcionan como esquemas de referencia (Schutz, 1987, p. 12). Por su parte, Cefaï (1994, p. 112) se refiere a las situaciones en las que esta reserva de experiencias no provee elementos para interpretar una nueva situación. El problema adviene cuando el actor no sabe qué decir o qué hacer, no llega a comprender lo que le pasa, no logra entender ni ponerse de acuerdo con los otros, fracasa al intentar inscribir un tema en las estructuras de pertinencia adoptadas hasta el momento. (...) El experimenta la inadecuación de su 'preestructura de comprensión': su campo de anticipación interpretativa y motivacional no es apropiada para definir y controlar la situación a la que tiene que hacer frente. 
Otros, por ejemplo, continuaban enviando a sus hijos al colegio privado al mismo tiempo que manifestaban deficiencias en salud, vestimenta y actividades de recreación. Se observaba que algunos, pese a sufrir la degradación total de las condiciones de hábitat, disfrutaban de una atención de salud de buena calidad y no era improbable encontrar quien combinara el endeudamiento generalizado con la concurrencia a un club deportivo y con la renovación periódica de su vestuario. ¿Qué había sucedido? ¿Acaso se había producido una desestructuración doméstica tal que había trastrocado las jerarquías de necesidades clásicas? No se trataba de eso; el aparente desorden de prioridades emanaba del tipo de recursos alternativos con los que esos nuevos pobres contaban y que provenían del capital cultural y sobre todo del capital social acumulados en el pasado. Esos recursos, a diferencia del dinero, no admitían fraccionamiento, por ser limitados. Así, por ejemplo, pertenecer a una familia con profesionales de la salud o poseer una red de amigos empresarios textiles permitía obtener respuestas específicas y predeterminadas ante ciertas necesidades, pero no era utilizable ante otras. Ahora bien, muchos de los tipos de capital a los que se echaba mano en la nueva situación habían sido acumulados en una situación social anterior y con fines diferentes y otros jamás habían sido previstos como tales.

Si se compara lo descrito con la relación entre pobreza y clientelismo político, puede decirse que este último ha sido tradicionalmente considerado como una de las formas de distribución informal de bienes y servicios los sectores pobres. El clientelismo es posible gracias al manejo discrecional de medidas asistenciales en zonas de alta concentración popular y con peso cuantitativo en los comicios. Pero tales transacciones parecen menos factibles con los nuevos pobres, que no están concentrados geográficamente ni son objeto de políticas sociales específicas. En su caso son los individuos mismos los que deben negociar en las instituciones públicas, intentando obtener bienes escaso o beneficios adicionales, $\mathrm{o}$ simplemente tratando de aminorar los inconvenientes de su utilización. En tal sentido, hemos atribuido al capital cultural, bajo la forma de "estado incorporado", 10 una serie de ventajas que observamos en instituciones como

\footnotetext{
${ }^{10}$ Para Bourdieu (1979) el capital cultural existe bajo tres formas, de las cuales nos interesa una: como estado incorporado (es decir, bajo la forma de disposiciones duraderas del organismo), en la disposición que hace referencia a actitudes, inclinaciones a percibir, sentir, hacer y pensar, interiorizadas por los individuos a partir de sus condiciones objetivas de existencia y que funcionan como principios inconscientes de acción, de percepción y de reflexión (Accardo y Corcuff, 1986, p. 229).
}

la escuela, los hospitales o las mutuales sindicales. Estos beneficios eran evidentes cuando se comparaba en una misma institución el desempeño de los nuevos pobres con el de los pobres estructurales. A los primeros, la movilización del capital cultural y social les permitía en el hospital obtener más fácilmente turnos con especialistas, lugares de internación, medicamentos gratuitos. En las escuelas públicas de mayor prestigio, pugnaban con mayor éxito por una plaza para sus hijos, también entre las pocas existentes de jornada completa (codiciadas por las familias en las que ambos padres trabajan) y en los jardines maternales para niños menores de cuatro años, instituciones que no están obligadas a atender a toda la población porque no forman parte de la educación obligatoria. En las oficinas municipales, los conflictos observados se producían por la distribución de bienes, ayudas y subsidios económicos y en el seguro de salud por conseguir que la institución se hiciera cargo de alguna prestación cuya cobertura no estaba claramente definida en los estatutos.

De los nuevos pobres entrevistados varios señalaron que lograban establecer relaciones de cierta complicidad con personal burocrático que les daba un trato preferencial. No obstante, la mayor parte de las negociaciones tenían un carácter conflictivo. Las disputas comenzaban en general cuando un usuario disconforme realizaba una "toma de palabra" ante la imposibilidad económica de optar por la "salida" y utilizar un servicio privado (Hirschman, 1970). Los usuarios interpelaban en alta voz al prestador, expresando con energía su opinión sobre las obligaciones de ese rol: cómo debía realizar su tarea, particularmente en cuanto al trato del usuario, la información que debía manejar, con qué rapidez, entre otras cosas. Del rol del personal podían pasar a las obligaciones de la institución en general y, en ciertos casos, sazonaban su discurso sobre sus "derechos" en tanto usuarios con el "respeto" y la "consideración" particular que se les debía por su posición social, calificación profesional u otro atributo que pudiera distinguirlos y elevarlos por encima de la masa indiferenciada de usuarios. No era raro que amenazaran con quejarse y "denunciar" a los empleados, pero no siguiendo los canales habituales (libros de quejas) sino por la llegada directa a instancias superiores, de las que muchos aseguraban tener un conocimiento personal.

A pesar de sus esfuerzos, persistía en ellos la incertidumbre sobre la eficacia de las estrategias ya desplegadas y cada nueva interacción relatada era una nueva experiencia de ensayo y error. Ningún atributo era siempre capital cultural ni dejaba de serlo, antes de probar su eficacia. Todo atributo probado con éxito en 
una oportunidad (el diploma, la posición profesional, una vaga referencia al derecho o a la ciudadanía) podía transformarse en capital mediante una operación de valorización exitosa, para dejar de serlo en la siguiente tentativa (en una institución distinta, o en la misma con otro prestador o hasta con el mismo) incluso hasta provocar un llamado al orden del prestador, recordándole que "todos tienen igual derecho".

En lo que respecta al capital social, su utilización por los nuevos pobres se orientaba a conseguir bienes y servicios habituales cuyo acceso ya no les era asequible por intercambios de mercadocorrientes. Por ello, identificaban posibles prestadores entre sus conocidos, estructurando redes personales que les permitían suplir algunas de sus carencias. El análisis de esas redes personales muestra que no se intentaba establecer a través de ellas relaciones de intercambio por fuera del mercado - como las relaciones de reciprocidad clásicas de los estudios de sectores marginales en América Latina (Lomnitz 1975)—, sino más bien flexibilizar las reglas normales de intercambio para obtener descuentos, pago en infinitas cuotas y hasta algunos trueques, en general cuando se trataba de profesionales prestadores de servicios. Como decíamos, aquello que en situación de empobrecimiento se transforma en capital cultural o social, en realidad corresponde a atributos acumulados en el curso de una situación social diferente, con otros fines o ni siquiera previstos como recursos. A título ilustrativo, tomemos el caso de un profesional que busca progreso laboral. En este caso, un capital social valioso incluiría un importante número de colegas. Ahora bien, si el profesional en cuestión se empobrece y busca amortiguar la caída de su nivel de consumo, ese capital acumulado (los colegas) perderá valor, ya que para cubrir sus necesidades insatisfechas sería más útil una variedad de perfiles profesionales, sinónimo de una amplia gama de eventuales prestaciones. Además, con el cambio de situación, los favores que se soliciten irán siendo de naturaleza muy diferente (por ejemplo, pasar de pedir una recomendación a solicitar dinero). No es posible prever si quien accedía a brindar los servicios de otrora aceptará satisfacer la nueva demanda.

La teoría del capital social y cultural presupone un contexto estable, en el cual se produce una acumulación de, por ejemplo, relaciones sociales con un fin predeterminado: la movilidad ascendente o la supervivencia en la pobreza. El empobrecimiento es un cambio de contexto que deja en suspenso la eficacia del capital social acumulado, cuya reconversión no es automática. En términos conceptuales, la nueva pobreza pone en evidencia la incertidumbre sobre el valor de los recursos a los que se puede echar mano, cuya utilidad y definición como capital solo se verificará cuando se realice cada operación de valorización. La dificultad de estabilizar los nuevos recursos resultó más acuciante para quienes se empobrecieron en la crisis del 2001. La caída fue tan repentina, violenta y extendida que, en general, no hubo tiempo para elaborar las estrategias adaptativas descritas. A la vez, por el gran número de personas afectadas, no fue posible conformar las redes personales que se estaban articulando cuando se produjo una movilidad descendente menos abrupta y masiva (Cortés y Kessler 2004).

\section{La erosión de la identidad social}

¿De qué manera los individuos empobrecidos definen el lugar que ocupan ahora en la estructura social? ¿La pauperización afecta a identificaciones sociales previas? ${ }^{11}$ Los nuevos pobres entrevistados se preguntaban $-\mathrm{y}$ preguntaban a los sociólogos-quiénes eran ellos ahora. No hay una respuesta única ni socialmente tipificada. A diferencia de lo que ocurre con el desempleo, en los procesos de empobrecimiento sin pérdida del trabajo no hay un "rito de destitución", como el despido, que es simultáneamente supresión de una categorización existente y base para una nueva (por ejemplo, el paso de gerente general a profesional desocupado). No obstante, se pudo observar que la pauperización cuestionaba una autotipificacion fundamental: la pertenencia a la clase media, íntimamente ligada a la definición de la identidad social argentina. Durante la hiperinflación de 1989 y 1990, el "fin de la clase media" era el fantasma de la aniquilación de un estrato y del proyecto de país que ella encarnaba (Sigal y Kessler, 1997). Su desaparición transformaría a Argentina en Brasil, al pasar de una situación de equilibrio ternario al enfrentamiento dicotómico entre la clase alta y la baja. La hiperinflación fue un fenómeno arrasador que al no dejar indemne a casi ningún grupo social, contribuyó a que el interrogante sobre la clase media se enunciara en forma colectiva, como el fin de toda la clase. La pauperización, en cambio, es un proceso de larga duración visible como problema

\footnotetext{
${ }^{11}$ Con estas preguntas nos referimos a su "autoclasificación social", es decir, a su inscripción en una categoría social determinada, como la de miembro de la "clase media" o "pobre". La autoclasificación es una ubicación imaginaria en la estructura social y un posicionamiento respecto a otros grupos sociales con los cuales se comparte el mundo social: por ejemplo, la categoría clase media supone e implica la coexistencia con una clase baja y una alta. Por ende, una mutación de la autoclasificación puede entrañar un cambio en la visión de toda la estructura social.
} 
social solo al cabo de cierto tiempo, lo que llevó a que en las entrevistas la pregunta se formulara más en términos individuales, es decir, referida a la propia permanencia o expulsión de la categoría. En rigor, no se planteaba como una pregunta única, sino como el cuestionamiento en cadena de las identificaciones ligadas a la idea de "clase media". Así, la pregunta inicial sobre la permanencia en esta clase obligaba al entrevistado a definir los criterios imaginarios de inclusión: ¿era la posición pasada, los diplomas o el nivel cultural? En seguida se le preguntaba por el alcance del cambio: ¿había sido individual, de todo un grupo social o de la sociedad en su conjunto? Por último, si él concluía que había habido expulsión, ¿cuál era el nuevo lugar de arribo?

En el origen de ese cuestionamiento estaba la supresión de determinados consumos. La autoinclusión en la clase media se basaba en el acceso — real o potencial-a bienes y servicios más allá de la mera supervivencia, tales como ciertas vestimentas, salidas, vacaciones, aparatos electrodomésticos y automóvil. Y si bien el nivel educativo era importante, el consumo era definitorio. De un lado, porque se pertenecía a la clase media aun sin la posesión de algún diploma; y, de otro, porque ante la crisis del estilo de vida ni siquiera una importante calificación educativa evitaba el cuestionamiento de dicha identificación. El empobrecimiento demostró que la autopercepción de que se pertenecía a la clase media se definía en la cotidianeidad de los hábitos de consumo: esa era la base de su gran popularidad en tiempos normales pero también de su extrema fragilidad en períodos de empobrecimiento. En efecto, la autoinclusión no precisa de ningún rito instituyente, pero en períodos de crisis su permisividad de entrada es su talón de Aquiles, no habiendo diploma ni posición institucional alguna que sea totalmente eficaz como dispositivo de retención.

De todos modos, en nuestras investigaciones las respuestas fueron de dos tipos: las de quienes sostenían su permanencia a rajatabla y las de quienes se consideraban expulsados. Los primeros aducían atributos que compensarían la pérdida del nivel de vida: los diplomas, la posición laboral, el nivel cultural, las costumbres, el pasado. Algunos se referían a una "devaluación masiva de la clase media" que, en conjunto, habría empeorado sus condiciones de vida, pero sin por ello cuestionar su propia pertenencia a ella ni la existencia de la clase media como estato diferenciado, solo que ahora era una "clase baja alta". Se trataba de un cambio colectivo más que de una expulsión individual, puesto que perduraría la división ternaria de la estructura social con un tercer segmento entre la clase alta y la clase baja, aunque su posición relativa descendiera, acercándose más a la clase baja. Definida la clase media en términos relativos y jerárquicos, pertenecer a ella implicaba plegarse a los límites de su definición imaginaria. Así interpretábamos la negativa de muchos entrevistados a considerarse sujeto legítimo de políticas asistenciales, como la distribución de alimentos gratuitos. Incluso familias en situación de intensa pobreza consideraban que "eso no era para ellos", sino para los "verdaderos pobres". La medida asistencial los etiquetaría; al rechazarla, trataban de evitar el estigma.

En contraposición, para los que se consideraban expulsados, la clave de pertenencia era el "estilo de vida". La autoexclusión era más frecuente entre los que no poseían diplomas o puestos calificados, aquello que facilitara compensar en la definición de su identidad el deterioro de las condiciones de vida. Desde situaciones objetivamente cercanas, había quienes adoptaban una u otra posición, según si hacían hincapié en las pérdidas o en lo que perduraba ("soy un profesional a pesar de todo"). Una vez (auto)decretada la expulsión, había que buscar una nueva categoría de acogida. No es de extrañar que en ningún caso se considerasen "pobres": los pobres eran los estructurales, de los cuales los separaba tanto un pasado como el estilo de vida presente. Lo híbrido de la nueva pobreza posibilitaba la variedad de respuestas a la pregunta sobre identificación social. A veces, ante la imposibilidad de decidir entre clase media y "clase pobre", se incluían en clase trabajadora, lo que implicaba un cambio en los parámetros de clasificación: del estilo de vida al origen de los ingresos (trabajo asalariado). Sin embargo, más que obtener respuestas acabadas, se observaba una situación de duda, una suerte de puesta en suspenso de la identidad social.

Esta situación caracterizó el fenómeno de la nueva pobreza a mediados de los años 1990. En trabajos realizados a mediados del 2002 ya se advertían algunos cambios interesantes. En primer lugar, la idea de expulsión de la clase media era casi mayoritaria y, sobre todo, muchos se consideraban ellos mismos como nuevos pobres (González Bombal, 2002). En efecto, la categoría había rebasado el campo académico y se habían apropiado de ella aquellos a los que nombraba, hasta el punto de que una investigación del año 2005 sobre percepción de identidad social señalaba que el 33\% de los entrevistados se había definido como "clase media empobrecida" (Grupo CCR, 2005). ${ }^{12}$ El

\footnotetext{
12 Nótese que un $12 \%$ se percibía como clase baja y un 55\% se consideraba clase media, lo cual muestra la permanencia de dicha clase como categoría de identificación privilegiada. En el momento de la encuesta las tasas oficiales de pobreza eran del $43 \%$.
} 
cambio de identidad social se daba a la vez con una distensión de las estrategias para diferenciarse de los "verdaderos pobres", marcada principalmente por el cambio de actitud frente a las políticas asistenciales a las que antes los nuevos pobres se negaban a acudir. Así lo demuestra el hecho de que estuvieran recurriendo, aunque minoritariamente por las exigencias de elegibilidad, al Plan Jefas y Jefes de Hogar Desocupados, programa de transferencia masiva de ingreso puesto en marcha tras la crisis del 2001. ${ }^{13}$

Ahora bien ¿qué pasa hoy con esa identidad social? ¿Se ha recompuesto entre los empobrecidos junto con estabilizarse la situación económica? En trabajos de los últimos años se describen las transformaciones socioculturales de las franjas ascendentes de las clases medias argentinas desde los años 1990. Ellos destacan un mayor individualismo, un acentuado consumismo, estrategias para evitar sectores populares y una socialización restringida, cuya imagen más paradigmática son los nuevos barrios y urbanizaciones privadas (Svampa, 2004; del Cueto, 2007). En relación al consumo, ha habido una dispersión de los bienes, otrora indicadores de estratos medios y altos, hacia franjas inferiores de la estructura social merced al abaratamiento y acceso al crédito, ${ }^{14}$ proceso comparable al descrito en páginas anteriores respecto a Brasil. Tanto es así que desde el 2006 las empresas de estudios de mercado han convenido en no utilizar más el acceso a bienes de consumo durables como indicador de estratificación, sino recurrir a otras variables, como la afiliación a servicios de salud de alto costo o el mayor o menor uso de mano de obra. En efecto, bienes como el teléfono de línea, el celular y los electrodomésticos clásicos (heladera, cocina y lavarropa) están extendidos y ya casi no marcan verdaderas fronteras entre estratos. Otros, por el contrario, como computadores, acceso a Internet o automóvil están desigualmente distribuidos entre una clase media estable y la franja empobrecida (Grupo cCR, 2005). No obstante, el abaratamiento paulatino de ciertos bienes augura que pronto los nuevos estratos accederán también a ellos. La pregunta que resta por responder es si esto indica que los sectores medios empobrecidos y hoy en parte estabili-

\footnotetext{
${ }^{13}$ En una investigación del 2007 restringida a la población beneficiaria de planes asistenciales de la comunidad judía, mayoritariamente nuevos pobres, el $24 \%$ era además beneficiario del Plan Jefas y Jefes de Hogar Desocupados u otro similar del gobierno de la Ciudad de Buenos Aires (Kessler, 2008).

${ }^{14}$ A pesar de esta mayor distribución de bienes en la estructura social, Mora y Araujo (2007) encontró en un estudio previo a la crisis que los principales hiatos se registraban entre los sectores medio alto y medio bajo y entre este último y el sector bajo.
}

zados están recuperando formas anteriores de construir identidad a partir de un renovado acceso al consumo o si, por el contrario, se están desplazando los indicadores de estatus y está comenzando a construirse la identidad de clase de estos sectores en torno a nuevos consumos y prácticas sociales, y ya no a los tradicionales bienes de consumo durables. En otras palabras, falta aún indagar si la generalización de ciertos bienes que otrora generaban distinción ayuda a reconstruir la identidad social de los empobrecidos o si, por el contrario, la reciente autotipificación de nuevo pobre se verá alterada por el acceso a determinados bienes de consumo, similares a los que en el pasado hubieran servido justamente para afirmar la pertenencia de clase.

\section{La dimensión urbana de la nueva pobreza}

Una cara poco explorada de la nueva pobreza es la distribución espacial de la diversidad de situaciones y formas que asume y su relación con el acceso al hábitat y a los servicios urbanos. Cabe resaltar que la nueva pobreza escapa a la lógica que por décadas fue el rasgo característico de la pobreza urbana en Argentina: villa = pobreza. La presencia de las "villas miseria" en la ciudad expresa territorialmente la posición que las personas ocupan en la estructura social. La nueva pobreza rompe con esta lógica característica de la pobreza estructural, puesto que ahora la posición social no se traduce necesariamente en formas estandarizadas de ocupación del territorio ni en condiciones uniformes de acceso al hábitat y a los servicios urbanos. La nueva pobreza, más difusa y más escondida que la pobreza estructural, modifica los usos y prácticas de la ciudad y en la ciudad, generando una nueva conflictividad en la vida urbana (Prevot Schapira, 2002).

En el Área Metropolitana de Buenos Aires, según datos del SIEMPRo (2001), el 91\% de los hogares pobres por insuficiencia de ingresos vive en barrios con trazado urbano. Solo el 9\% de los hogares pobres se radica en villas de emergencia o en asentamientos precarios. Sin embargo, cuando se analiza la composición de cada una de estas formas de urbanización se observa que el $26,8 \%$ de quienes viven en barrios con trazado urbano son pobres por insuficiencia de ingresos. ${ }^{15}$

En este marco se puede pensar que las lógicas territoriales de la pobreza estructural y de la nueva pobreza son diferentes, aun cuando no es posible concebirlas

\footnotetext{
${ }^{15}$ Entre los hogares asentados en villas ese porcentaje asciende al $59,1 \%$.
} 
como "mundos" enteramente aislados. Varias décadas de empobrecimiento y el efecto del desempleo han roto el esquema que confinaba a los pobres a territorios bien delimitados y claramente identificables. La pobreza en los años 1990 se expresa en los intersticios de la ciudad y se manifiesta en un proceso de deterioro y transformación del parque habitacional existente, que incluye la lenta alteración del uso y el estado de las estructuras materiales. ${ }^{16}$ Los hogares permanecen en los tradicionales barrios de clases medias y, si tienen suerte, mantienen en propiedad su vivienda; sin embargo, están imposibilitados de introducir mejoras, de invertir en mantenimiento e incluso se ven obligados a hacer modificaciones en los ambientes de la casa para generar pequeños espacios productivos, como talleres o pequeños comercios.

El deterioro de las estructuras materiales y las alteraciones en su uso evolucionaron en paralelo con el cambio en la lógica de acceso a la ciudad que había guiado tradicionalmente a los sectores medios. Estos sectores se habían asegurado el acceso a la ciudad en general y al hábitat en particular a través de una lógica de mercado: es decir, el mercado era el mecanismo social por el cual lograban acceder a la vivienda y a los servicios urbanos. Las experiencias de pauperización tensionaron fuertemente sus posibilidades de recurrir a mecanismos de mercado, en particular cuando esa pauperización ha sido tributaria del desempleo. Como señala Badcock (1984, p. 171), la estructura del empleo y la posición que ocupan las familias en ella condicionan fuertemente el acceso al hábitat. En un contexto en el cual el desempleo ha afectado a vastos sectores de la población (alcanzando en algunos momentos al 21,5\% de ella), los mecanismos tradicionales de acceso al hábitat y a los servicios urbanos se han visto bloqueados. ${ }^{17}$

La crisis de los mecanismos sociales tradicionales de acceso al hábitat se ha expresado en fenómenos tales como la ocupación de inmuebles. En las últimas dos décadas se ha observado que los pobres en Buenos Aires se han apropiado de pequeños espacios vacantes en las zonas centrales de la ciudad, como propiedades fiscales, edificios abandonados por sus propietarios, fábricas y galpones, los que utilizan como viviendas. A menudo estos inmuebles carecen de instalaciones sanitarias y

\footnotetext{
${ }^{16} \mathrm{El}$ aumento de los porcentajes de hacinamiento es una de las expresiones de la pobreza dentro del hábitat formal.

${ }^{17}$ La densificación de las villas de emergencia, que se produjo fundamentalmente entre fines de la década de 1990 y el año 2005, puede haber contribuido al quiebre de esa lógica: familias empobrecidas que antes que abandonar la ciudad, optan por habitar espacios segregados.
}

eléctricas adecuadas y suele haber interrupciones del abastecimiento de agua y energía eléctrica por falta de pago. En estos casos, a pesar de que se disfruta de los beneficios de vivir en la ciudad, las condiciones de vida se ven seriamente deterioradas por la incertidumbre respecto a los medios de subsistencia y a la calidad de la vivienda (Herzer y Di Virgilio, 1996; Rodríguez y Di Virgilio, 2006).

A lo anterior se sumó el retiro del Estado de la prestación de ciertos servicios públicos que hasta la década de 1990 regularon algunos estándares mínimos de condiciones de vida y que hoy tienen un alcance muy limitado. A partir de dicha década y en el marco de procesos de reforma del Estado, la lógica interna de reproducción de las ciudades experimentó cambios significativos. La masiva privatización de los servicios desplazó la gestión de los consumos colectivos urbanos hacia la órbita del mercado y llevó a una mercantilización de los servicios urbanos básicos. En este nuevo escenario, que transfiere los costos de vivir en la ciudad formal al salario directo de los trabajadores (Catenazzi y Di Virgilio, 2006), el acceso a dichos servicios está regulado casi exclusivamente por la capacidad de los hogares de obtener ingresos suficientes para cubrir una canasta básica de bienes y servicios.

En ese marco, los hogares disminuyeron el uso de los servicios de infraestructura: agua, gas, electricidad, telecomunicaciones y transporte. La reducción del poder adquisitivo de los grupos de menores ingresos significó el descenso de los gastos en alimentación y en el cuidado de la salud, así como una caída aún mayor de la capacidad de estos grupos para financiar mejoras de las condiciones de vivienda o bien para mantener el pago de la vivienda y de los servicios mismos.

Por otro lado, los límites en la acción del Estado se manifestaron también en el deterioro de la capacidad de las instituciones públicas de la ciudad — como la escuela, el hospital, la obra de protección social— para procesar las demandas de los sectores empobrecidos, entre otras causas, por falta de personal e insumos y la supresión de algunas prestaciones. En las entrevistas, los nuevos pobres se quejaban de que concurren a hospitales donde se sigue operando pero en los que no hay ni camas disponibles, ni gasas ni medicamentos; llaman a servicios de urgencia que todavía existen pero que carecen de ambulancias; envían a sus hijos a escuelas que siguen abiertas pero en que ciertas materias no se dictan, hay meses sin clases o la maestra parece desinteresada de su tarea; ahorran para comprar sofisticadas alarmas que suenan en el comisariado cuando entran los ladrones, pero la policía no acude, y recurren a oficinas públicas 
que siguen en los lugares de siempre pero cuyo personal en gran parte ha desaparecido.

La vastedad del empobrecimiento y sus experiencias no debe hacernos olvidar que otra parte de la clase media "empató", es decir, no vio variar en demasía su situación, y que una franja minoritaria ascendió en los años 1990. Nada lo ilustra más claramente que el aumento de la desigualdad en la distribución de los ingresos a lo largo de la década: en sus inicios el ingreso per cápita medio del $10 \%$ de hogares más ricos era aproximadamente veinte veces el correspondiente al 10\% de hogares más pobres, relación que pasó a ser de treinta veces hacia el final del decenio (Altimir y Beccaria, 1999). Entre los "ganadores" se encontraban sectores medios ubicados en las áreas más dinámicas de la economía. Svampa (2002 y 2004) estudió dicho estrato a partir del proceso de suburbanización que protagonizó en la década de 1990 hacia los más de cuatrocientos nuevos barrios privados y country clubs que surgieron en los alrededores de Buenos Aires y otras grandes ciudades del país. Se trata de un fenómeno que fue advertido hace años en urbes latinoamericanas como São Paulo, México, D.F. y Caracas, donde alcanzó mayor magnitud en la década de 1990, y que se ha extendido posteriormente a otras ciudades, como Santiago de Chile y Buenos Aires.

Para comprender el empobrecimiento en un contexto general hay que tomar en cuenta lo que ha sucedido con las otras fracciones de la clase media. En ese sentido, cabe señalar que el proceso de suburbanización está afectando a toda la fisonomía urbana argentina. Hubo un desplazamiento desde un modelo de "ciudad abierta", básicamente europeo, centrado en la noción de espacio público y en valores como la ciudadanía política y la integración social, hacia un régimen de "ciudad cerrada", según el modelo estadounidense marcado por la afirmación de una ciudadanía privada, que refuerza la fragmentación social. Durante mucho tiempo, en Argentina este modelo de ciudad abierta se asentó, aun con sus deficiencias, en una matriz social que suponía el reconocimiento explícito de una sociedad democrática. Pero en la década de 1990, como resultado del proceso de suburbanización, los sectores medios ganadores empezaron a disminuir sus lazos con sus pares en peor situación y a vivir en áreas antes reservadas a sectores tradicionalmente altos. Sin duda, esto terminará de diluir lo que resta de la homogeneidad cultural de la antigua clase media. En efecto, en las nuevas comunidades cerradas la clase media exitosa comenzó a codearse con la antigua clase alta. Como advierte Svampa (2002 y 2004) pese a las diferencias en términos de capital (sobre todo económico y social) y la antigüedad de clase, las clases altas y una franja exitosa de las clases medias llegan a ser partícipes comunes de una serie de experiencias en cuanto a patrones de consumo, estilos residenciales y, en algunos casos, entornos de trabajo. En otras palabras, de los marcos culturales y sociales que dan cuenta de un entramado de relaciones que se halla en la base de nuevas formas de sociabilidad.

\section{$\mathrm{V}$}

\section{A modo de cierre: la nueva pobreza hoy}

Luego de este recorrido cabe preguntarse qué cambios pueden advertirse en los nuevos pobres al comparar los primeros estudios y los más actuales. Ante todo, en Argentina la nueva pobreza ya no es nueva hoy como fenómeno social. Cabe recordar que durante la crisis del 2001 se produjo una nueva gran oleada de empobrecidos, de forma más violenta que en la crisis anterior y con más conciencia de lo que estaba sucediendo. Muchos empobrecidos llevan ya más de una década de pauperización, lo que ha generado problemas sociales producto de años de caída, como el aumento de la enajenación de inmuebles y otras propiedades por deudas acumuladas durante años, lo que se observa en los grandes centros urbanos. En segundo lugar, muchos derroteros de movilidad descendente vistos a comienzos de la década de
1990 hoy aparecerían como trayectorias inestables. Según un trabajo sobre movilidad ocupacional en Argentina (Kessler y Espinoza, 2007), ciertos individuos empobrecidos a comienzos de los años 1990 vieron mejorar su situación en fases de crecimiento posteriores y luego volvieron a caer, siendo su trayectoria y su experiencia distintas a la de una caída sin puntos de retorno parcial. Asimismo, en esa década se registró un proceso de movilidad estructural ascendente, es decir, un incremento absoluto y relativo de puestos considerados de clase media por el nivel de calificación requerido (Torrado, 1994). Pero a la vez disminuyeron los beneficios y niveles de bienestar de tales puestos debido a la degradación de los ingresos y la precarización general del trabajo. Por lo tanto, en muchos casos hubo movilidad ascendente 
intergeneracional o intrageneracional en cuanto al nivel de calificación del puesto ocupado, pero sin que se ganara - o incluso perdiendo - bienestar respecto del pasado, dando origen a lo que se ha llamado movilidad espuria (Kessler y Espinoza, 2007).

En tercer lugar, a comienzos de los años 1990 la nueva pobreza era un fenómeno de "puertas adentro" que no generaba acciones ni estrategias colectivas. Ya en el año 2000, como lo muestra González Bombal (2002) en su estudio sobre el Club del Trueque - experiencia de intercambios de bienes y servicios que llegó a reunir dos millones de personas en el 2001-, los sectores medios empobrecidos cruzaron la puerta y se organizaron en estrategias colectivas. Los clubes del trueque fueron un ámbito privilegiado para observar la interacción de sectores medios empobrecidos y sectores populares. Estos últimos accedían a ciertos servicios (como terapias tradicionales y alternativas, trabajo corporal) propios de los sectores medios urbanos argentinos, quienes, de su lado, trocaban esos servicios por bienes (como comida casera) y otros tipos de servicios más afines a los sectores populares (arreglos del hogar, mantenimiento). Sin embargo, el sentido otorgado a este intercambio por cada clase era diferente: mientras para los sectores populares significaba una suerte de ascenso social al acceder a sectores y prácticas identificadas con la clase media, para los empobrecidos era un indicador más de que la expulsión tan temida finalmente había tenido lugar (Luzzi, 2005). Una experiencia masiva de salida de la clase media, que incluyó la de los empobrecidos, fue la conformación de asambleas barriales luego de la crisis del 2001 en la ciudad de Buenos Aires y ciertos lugares del Conurbano y ciudades del interior. Como sostiene Svampa (2005), las asambleas barriales fueron un espacio de organización y de deliberación que rompía con las formas tradicionales de representación política y favorecía otras formas de auto-organización de lo social, con aspiraciones a la horizontalidad y proclives al ejercicio de la acción directa. Estas nuevas experiencias reposicionaron a las clases medias, sobre todo de la ciudad de Buenos Aires, en un lugar importante de la escena política, aunque con duración acotada.

El análisis de lo sucedido con las clases medias como fenómeno novedoso en los años 1990 no debe opacar una mirada rápida sobre lo que ocurría con la pobreza de vieja data, es decir, con los pobres estructurales. En este sentido cabe una autocrítica a quienes estudiamos las cuestiones de pobreza en la década de 1990. La novedad de lo que sucedía con las categorías socioprofesionales medias concentró tanto nuestra aten- ción que fallamos en mirar más allá y analizar el impacto del empobrecimiento en toda la estructura social. En concreto, el empobrecimiento de los sectores medios y su salida de ciertos puestos al aumentar el desempleo, hizo que los pobres de vieja data se vieran desplazados a puestos de baja calificación; otros puestos, producto de la modernización, fueron siendo recalificados y, por ende, no pudieron seguir siendo ocupados por pobres con bajo nivel educativo. En esta situación de competencia en el mercado de trabajo los pobres estructurales perdieron elegibilidad, y puestos ocupados tradicionalmente por sectores bajos pasaron a manos de sectores medios empobrecidos pero más calificados. Porcú (2003) rastreó el impacto del empobrecimiento de la clase media en los más pobres (la desocupación en el servicio doméstico, por ejemplo). La estrategia a la que habían apelado los hogares pobres en etapas anteriores - la de complementar el ingreso del jefe de hogar con el trabajo de la mujer en servicio doméstico, o suplirlo en casos de crisis de desempleo- también se vio perjudicada por el empobrecimiento de los sectores medios.

Por último, un aspecto que parece desprenderse con contundencia de este artículo es que la nueva pobreza plantea grandes interrogantes a las políticas públicas en los diversos países, interrogantes que - aun en el caso de Argentina con más de una década de empobrecimiento- no se han traducido en políticas novedosas. Tales políticas deben incorporar componentes territoriales, pues la ciudad y las lógicas de acceso a ella también se han visto fuertemente impactadas. Sin duda, en el nuevo contexto las políticas exigen máxima creatividad puesto que ciertos criterios habituales, como la focalización tradicional de base territorial en los hábitat de alta concentración de pobres, no son útiles para una población dispersa en los intersticios de la ciudad. Genera desazón entre quienes venimos siguiendo el fenómeno hace años cómo a pesar de que el tema está instalado en la agenda pública y en el sentido común de la sociedad, no se han generado políticas públicas para esta población. No se nos escapa la existencia ni el incremento de la pobreza más dura en los años anteriores, para cuyo tratamiento las políticas tampoco son suficientes, pero ya nuestros trabajos de hace una década mostraban que parte del impresionante deterioro de la situación de los hogares se debió en gran medida a la falta de políticas públicas preventivas. Si bien esta carencia no fue la causa inicial, no nos cabe duda de que una serie de medidas - no necesariamente muy costosas- hubiera permitido a los hogares empobrecidos amortiguar los efectos de la crisis y, sobre todo, evitar la acumulación de necesidades que más tarde hicieron eclosión. 
En nuestras investigaciones de mediados de los años 1990 observamos, por ejemplo, la falta de ayuda para pagar alquileres y expensas que llevaron posteriormente a desalojos y enajenación de propiedades; la carencia de recursos para afrontar deudas que, manejables en un primer momento, se volvían impagables después; las dificultades para afrontar y continuar tratamientos médicos que luego provocaron secuelas de por vida y hasta fallecimientos; la interrupción de los estudios de hijos jóvenes — supuestamente por un tiempo, para ayudar al hogar- pero que más tarde no eran reanudados, dando origen a un déficit de capital humano luego insalvable. A la vez, se iba produciendo un aislamiento paulatino de las relaciones de larga data por el "consumo" de un capital social que, al no poder establecer reciprocidad, se iba gastando. Así, cuando más hubieran necesitado los hogares empobrecidos de sus grupos de pertenencia, más se iban alejando de ellos. Retomando lo sostenido en la introducción de este trabajo, diremos que la experiencia argentina es paradigmática para procesos similares que de un modo u otro están produciéndose en la región. Sería deseable que los errores - por acción u omisión-que hemos cometido en Argentina sirvan para no repetirlos en otros países de la región, para evitar así el sufrimiento social de vastas capas de la población.

\section{Bibliografía}

Accardo, A. y Ph. Corcuff (1986): La sociologie de Bourdieu, Burdeos, Le Mascaret.

Altimir, O. y L. Beccaria (1999): Distribución del ingreso en la Argentina, serie Reformas económicas, No 40, LC/L.1276-P, Santiago de Chile, Comisión Económica para América Latina y el Caribe (CEPAL).

Attewell, P., D. Lavin y otros (2004): The black middle class: progress, prospects, and puzzles, Journal of African American Studies, vol. 8, $\mathrm{N}^{\mathrm{o}} 1-2$, Nueva York, Springer.

Auletta, K. (1982): The Underclass, Nueva York, Random House.

Badcock, B. (1984): Unfairly Structured Cities, Oxford, Blackwell.

Balsen, W., H. Nakielski y otros (1984): Die Neue Armut, Colonia, Bund Verlag.

Barthe, M-A. (1987): Les formes de la pauvreté dans la société française, Revue française des affaires sociales, $N^{\circ} 2$, París, Ministère des Affaires Sociales.

Bayón, C. (2006): Precariedad social en México y Argentina: tendencias, expresiones y trayectorias nacionales, Revista de la CEPAL, $\mathrm{N}^{\circ}$ 88, LC/G.2289-P, Santiago de Chile, abril.

Beccaria, L. y R. Mauricio (2005): Inestabilidad laboral en el Gran Buenos Aires, Trimestre económico, vol. 71, N²83, México, D.F., Fondo de Cultura Económica.

Blackburn, McK. y D. Bloom (1985): What is happening to the middle class?, American Demographics, vol. 7, No 1, Nueva York, Crain Communications, enero.

Bolt, G. y R. van Kempen (2003): Escaping poverty neighbourhoods in the Netherlands, Housing, Theory and Society; vol. 20, $\mathrm{N}^{\circ} 4$, Londres, Routledge.

Bourdieu, P. (1979): Les trois états du capital culturel, Actes de la recherche en sciences sociales, $\mathrm{N}^{\circ} 30$, París, Centre de sociologie européenne du Collège de France .

Bucheli, M. y M. Furtado (2004): Uruguay 1998-2002: características de los cambios en el perfil de la distribución del ingreso, serie Estudios y perspectivas, $\mathrm{N}^{\mathrm{o}}$ 1, LC/L.2162-P, Montevideo, Oficina de la cepal en Montevideo. Publicación de las Naciones Unidas, $\mathrm{N}^{\mathrm{o}}$ de venta: S.04.II.G.90.

Caldeira, T. (1996): Fortified enclaves: the new urban segregation, Public Culture, vol. 8, № 2, Durham, Duke University Press.

Carbonaro, A. (1979): Povertà e classi sociali. Per la critica delle ideologie sui processi di pauperizzazione, Milán, FrancoAngeli.

Castel, R. (1995): Les métamorphoses de la question sociale. Une chronique du salariat, París, Fayard.

Catenazzi, A. y M. M. di Virgilio (2006): Habitar la ciudad: aportes para el diseño de instrumentos y la definición de una política urbana, en L. Andrenacci (comp.), Problemas de política social ( $Y$ la política social en problemas), Los Polvorines, Universidad Nacional de General Sarmiento.

Cefaï, D. (1994): Type, typicalité, typification. La perspective phénoménologique, en Bernard Fradin, Louis Queré y Jean Widmer (comps.), L'enquête sur les catégories, París, École des Hautes Études en Sciences Sociales.

CELS (Centro de Estudios Legales y Sociales) (2001): La protesta social en la Argentina durante diciembre de 2001, documento presentado en la Audiencia sobre la situación general de derechos humanos en Argentina, ante la Comisión Interamericana de Derechos Humanos (CIDH), Buenos Aires.

Comunidad Económica Europea (1988): Social Europe, Bruselas.

Cortés, F. y A. Escobar Latapí (2005): Movilidad social intergeneracional en el México urbano, Revista de la CEPAL, N 85, LC/G.2266-P, Santiago de Chile, Comisión Económica para América Latina y el Caribe (CEPAL), abril.

Cortés, R. y G. Kessler (2003): Intervenciones sociales y acción comunitaria. Informe sobre situación de población empobrecida de la comunidad judía, Nueva York, American Joint Distribution Committee.

(2004): Informe sobre la situación de beneficiarios de planes asistenciales de instituciones comunitarias, inédito.

De Regt, A. y D. Weenink (2000): Angs voor sociale daling? De functies van particulier onderwijs [¿Miedo a la movilidad descendente? Las funciones de la educación privada.], Amsterdams Sociologisch Tijdschrift, vol. 27, № 3, Amsterdam, Stichting Amsterdams Sociologisch Tijdschrift.

Del Cueto, C. (2007): Los únicos privilegiados, Buenos Aires, Universidad Nacional de General Sarmiento (UNGs)/Prometeo.

Devine, J. y J. Wright (1993): The Gratest of Evil: Urban Poverty and the American Underclass, Nueva York, Aldine.

Di Virgilio, M. M. (2003): Hábitat y salud. Estrategias de las familias pobres, Buenos Aires, Ediciones Lumière.

Elder, G. (1974): Children of the Great Depression: Social Change in Life Experiences, Chicago, University of Chicago Press.

Espinoza, V. (2006): La movilidad ocupacional en el Cono Sur. Oportunidades y desigualdad social, Revista de Sociología, $\mathrm{N}^{\mathrm{o}} 20$, Santiago de Chile, Facultad de Ciencias Sociales, Universidad de Chile.

Feijoó, M. del C. (1992): Los gasoleros: estrategia de consumo de los NUPO, en A. Minujin (comp.), Cuesta abajo. Los nuevos pobres: efectos de la crisis en la sociedad argentina, Buenos Aires, UNICEF-Losada. 
(2001): Nuevo país, nueva pobreza, Buenos Aires, Fondo de Cultura Económica.

Fothergill, A. (2003): The stigma of charity: gender, class and disaster assistance, The Sociological Quarterly, vol. 44, N 4, Oxford, Reino Unido, Blackwell Publishing.

Gaffikin, F. y M. Morrisey (1992): The New Unemployed. Joblessness and Poverty in the Market Economy, Londres, Zed Books.

Germani, G. (1963): Movilidad social en la Argentina, en S. Lipset y R. Bendix (comps.), Movilidad social en la sociedad industrial, Buenos Aires, Eudeba.

González Bombal, I. (2002): Sociabilidad en clases medias en descenso: experiencias en el trueque, Sociedad y sociabilidad en la Argentina de los 90, Buenos Aires, Universidad Nacional de General Sarmiento (UNGs)/Biblos.

Grupo CCR (2005): Marcas masivas, mercados fragmentados, documento presentado en el $4^{\circ}$ Encuentro del Consumo Masivo, Buenos Aires, Instituto Argentino de la Empresa.

Herzer, H. M. y M. M. di Virgilio (1996): Buenos Aires: pobreza e inundación, en H. M. Herzer y M. M. di Virgilio, EURE: Revista Latinoamericana de Estudios Urbano Regionales, Santiago de Chile, Instituto de Estudios Urbanos, Pontificia Universidad Católica de Chile, diciembre.

Hirschman, A. (1970): Exit, Voice and Loyalty, Cambridge, Massachusetts, Harvard University Press.

Hoffman, K. y M. A. Centeno (2003): The lopsided continent: inequality in Latin America, Annual Review of Sociology, vol. 29, Palo Alto, California, Annual Reviews.

Ilkhamov, A. (2001): The impoverishment of masses in the transition period: signs of an emerging 'new poor' identity in Uzbekistan, Central Asian Survey, vol. 20, № 1, Londres, Routledge.

INDEC (Instituto Nacional de Estadística y Censos) (2003): [en línea] http://www.indec.gov.ar

Kazemipur, A. y Sh. Halli (2001): Immigrants and 'new poverty': the case of Canada, The International Migration Review; vol. 35, $\mathrm{N}^{\mathrm{o}}$ 4, Nueva York, Center for Migration Studies of New York, Inc.

Kaztman, R. (1989): La heterogeneidad de la pobreza en Montevideo: una aproximación bidimensional, La economía de América Latina, $\mathrm{N}^{\circ}$ 18, Montevideo, Facultad de Ciencias Económicas y de Administración, Universidad de La República.

Kaztman, R., F. Filgueira y otros (2005): La ciudad fragmentada. Respuesta de los sectores populares urbanos a las transformaciones del mercado y del territorio en Montevideo, en A. Portes, B. Roberts y A. Grimson (comps.), Ciudades latinoamericanas. Un análisis comparativo en el umbral del nuevo siglo, Buenos Aires, Prometeo.

Kelly, M. (1984): The Poor Aren't News, Dublín, Simon Community.

Kessler, G. (1998): Le processus de paupérisation de la classe moyenne argentine, tesis de doctorado, París, École des Hautes Études en Sciences Sociales.

(2000): Redefinición del mundo social en tiempos de crisis. Sobre el uso del capital social en clases medias empobrecidas, en M. Svampa (comp.), Desde abajo, Buenos Aires, Biblos/ Universidad Nacional de General Sarmiento (UNGS).

(2008): Infancias vulnerables, Buenos Aires, American Joint.

Kessler, G. y V. Espinoza (2007): Movilidad social y trayectorias ocupacionales en Buenos Aires. Continuidades, rupturas y paradojas, en R. Franco, A. Léon y R. Atria (coords.), Estratificación social en América Latina. Transformaciones estructurales de un cuarto de siglo, Santiago de Chile, CEPAL-LOM.

Kessler, G. y M. di Virgilio (2005): The new poverty in Argentina and Latin America, en L. Hanley, B. Ruble y J. Tulchin (comps.), Becoming Global and the New Poverty of Cities, Washington, D.C., Woodrow Wilson International Center for Scholar/Agencia de los Estados Unidos para el Desarrollo Internacional (USAID).
Kryshtanovkaia, O. (2005): Has-Beens: trends of downward mobility of the Russian elite, Sociological Research, vol. 44, $\mathrm{N}^{\circ} 2$, Armonk, M.E. Sharpe.

Ladanyi, J. e I. Szelenyi (2002): Ciganyok es szegeneyek Magyararoszagon, Romaniaban es Bulgarian [El origen y los determinantes sociales de la Pobreza Rom en una comparación trasnacional de Hungría, Rumania y Bulgaria], Szociological Szemle, $\mathrm{N}^{\circ} 4$.

Lomnitz, L. (1975): ¿Cómo sobreviven los marginados?, México, D.F., Siglo XXI.

Lomnitz, L. y A. Melnick (1991): Chile's Middle Class. A Struggle for Survival in the Face of Neoliberalism, Boulder, Colorado, Latin American and Caribbean Centre.

López, J. (1999): Evolución reciente del empleo en México, serie Reformas económicas, N² 29, LC/L.1218-P, Santiago de Chile, Comisión Económica para América Latina y el Caribe (CEPAL), julio.

Luzzi, M. (2005): Reinventer le marché? Les clubs de troc face à la crise en Argentina, París, L'Harmattan.

Marklund, S. (1990): Structures of modern poverty, Acta sociológica, vol. 33, $\mathrm{N}^{\mathrm{o}}$ 2, Thousand Oaks, Sage Publications.

McDowell, L. (2002): Transitions to work: masculine identities, youth inequality and labour market change, Gender, Place and Culture, vol. 9, $\mathrm{N}^{\circ}$ 1, Londres, Routledge.

McMahon, P. y J. Tschetter (1986): The declining middle class: a further analysis, Monthly Labor Review, vol. 109, № 9, Washington, D.C., Bureau of Labor Statistics.

Mead, L. (1986): Beyond Entitlements, Nueva York, The Free Press.

Mingione, E. y F. Zajczyk (1992): Le nuove povertà urbane in Italia: modelli di percorsi a rischio nell'area metropolitana milanese, Inchiesta, $\mathrm{N}^{\circ}$ 97-98, Bari, Dedalo.

Minujin, A. (comp.) (1992): Cuesta abajo. Los nuevos pobres: efectos de la crisis en la sociedad argentina, Buenos Aires, UNICEF-Losada.

Minujin, A. y G. Kessler (1995): La nueva pobreza en la Argentina, Buenos Aires, Temas de Hoy/Planeta.

Mitev, P-E. (2001): A szegenyseg dinamikaja [Dynamics of Poverty], Szociologial Szemle, $\mathrm{N}^{\mathrm{o}} 4$.

Molina, I. (2001): Segregación habitacional étnica en la ciudad sueca Un proceso de racialización, Scripta nova. Revista electrónica de geografía y ciencias sociales, $\mathrm{N}^{\circ}$ 90, Barcelona, Universidad de Barcelona.

Montero, S. y M. Barahona (2003): La estrategia de lucha contra la pobreza en Costa Rica. Institucionalidad - Financiamiento Políticas - Programas, serie Políticas sociales, No 77, LC/L.2009-P, Santiago de Chile, Comisión Económica para América Latina y el Caribe (CEPAL). Publicación de las Naciones Unidas, $\mathrm{N}^{\mathrm{o}} \mathrm{de}$ venta: S.02.II.G.170.

Mora y Araujo M. (2007): Evidencia y conjeturas acerca de la estratificación actual en Argentina, en R. Franco, A. Léon y R. Atria (coords.), Estratificación social en América Latina. Transformaciones estructurales de un cuarto de siglo, Santiago de Chile, CEPAL-LOM.

Mota Guedes, P. y N. Vierra Oliveira (2006): La democratización del consumo, Braudel Papers, № 19, São Paulo, Instituto Fernand Braudel de Economía Mundial.

Murray, Ch. (1984): Losing Ground, Nueva York, Basic Books.

Neef, R. (1992): The new poverty and local government social policies: a West German perspective, International Journal of Urban and Regional Research, vol. 16, № 22, Oxford, Reino Unido, Blackwell Publishing.

Newman, K. (1989): Falling from Grace. The Experience of Downward Mobility in the American Middle Class, Nueva York, Vintage Books.

(1993): Declining Fortunes. The Withering of the American Dream, Nueva York, Basic Books.

O'Dougherty, M. (1999): The devalued state and nation: neoliberalism and the moral economy discourse of the Brazilian middle class, 1986-1994, Latin American Perspectives, vol. 26, Nº 104, Thousand Oaks, Sage Publications 
O’Higgins, M. y S. Jenkins (1989): Poverty in Europe: estimates for the numbers in poverty in 1975, 1980, 1985, Bath, University of Bath.

Parrado, E. (2005): Economic restructuring and intra-generational class mobility in Mexico, Social Forces, vol. 84, No 2, Chapel Hill, University of North Carolina.

Paugam, S. (1991): La disqualification sociale. Essai sur la nouvelle pauvreté, París, PUF.

(1993): La société française et ses pauvres. L'expérience de revenu minimum d'insertion, París, PUF.

Porcú, P. (2003): Proceso de movilidad descendente de los noventa. El impacto de la pérdida del trabajo en los hogares pobres, tesis de maestría en diseño y gestión de políticas y programas sociales, Buenos Aires, FLACSO Argentina.

Portes, A. y Min Zhou (1993): The new second generation: segmented assimilation and its variants among post-1965 immigrant youth, Annals of the American Academy of Political and Social Science, vol. 530, Thousand Oaks, Sage Publications.

Prevot Schapira, M-F. (2002): Buenos Aires en los 90, metropolización y desigualdades, EURE: Revista de Estudios Urbano Regionales, vol. 28, No 85, Santiago de Chile, Pontificia Universidad Católica. Disponible en http://redalyc.uaemex.mx/redalyc/src/inicio/ ArtPdfRed.jsp?iCve=19608503\&iCveNum=503

Rodríguez, M. C. y M. M. di Virgilio (2006): Políticas de tierra y vivienda y déficit habitacional en el Área Metropolitana de Buenos Aires, Revista argentina de sociología, Buenos Aires, Consejo de Profesionales en Sociología, por aparecer.

Room, G. (1989): 'New Poverty' in the European Community, Londres, MacMillan.

Rosenthal, N. (1985): The shrinking middle class: myth or reality?, Monthly Labor Review, vol. 108, № 3. Washington, D.C., Bureau of Labor Statistics.

Sabatini, F. y G. Wormald (2005): Crecimiento, modernización y oportunidades de integración social, en A. Portes, B. y A. Grimson (comps.), Ciudades latinoamericanas. Un análisis comparativo en el umbral del nuevo siglo, Buenos Aires, Prometeo.

Sabogal, E. (2005): Viviendo en la sombra: the immigration of Peruvian professionals to South Florida, Latino Studies, vol. 3, No 1 , Houndmills, Palgrave Macmillan.

Schutz, A. (1987): Le chercheur et le quotidien, París, Méridiens Klincksieck.

SIEMPRo (2001): Encuesta de Condiciones de Vida (ECV). Base usuario, Buenos Aires, Ministerio de Desarrollo Social.

Sigal, S. y G. Kessler (1997): Comportements et représentations dans une conjoncture de dislocation des régulations sociales. L'hyperinflation en Argentine, Culture \& conflits, $\mathrm{N}^{\mathrm{o}} 24-25$, París, Centre d'Études sur les Conflits.

So, A. (2004): The middle class in Asia-Pacific: second phase and future trajectory, Asian Perspective, vol. 28, Nº 2, Seúl, Institute for Eastern Studies.

Søholt, S. (2001): Ethnic minority groups and strategies in the housing market in Oslo. European Journal of Housing Policy, vol. 1, $\mathrm{N}^{\circ}$ 3, Londres, Routledge.
Strobel, F. (1993): Upward Dreams, Downward Mobility. The Economic Decline of the American Middle Class, Lanham, Maryland, Rowman\&Littlefield Publishers Inc.

Svampa, M. (2002): Los que ganaron. La vida en los countries y barrios privados, Buenos Aires, Biblos.

(2004): La brecha urbana. Countries y barrios privados en Argentina, Buenos Aires, Colección Claves para Todos-Le Monde Diplomatique.

(2005): La sociedad excluyente. La Argentina bajo el signo del neoliberalismo, Buenos Aires, Taurus.

Tironi, M. (2003): Nueva pobreza urbana. Vivienda y capital social en Santiago de Chile, 1985-2001, Santiago de Chile, Universidad de Chile/ PREDES/ Ril Editores.

Titma, M. y R. Murakas (2004): Income inequalities in the Baltic states, International Journal of Sociology, vol. 34, $\mathrm{N}^{\circ} 2$, Armonk, M.E. Sharpe.

Torche, F. (2005): Unequal but fluid: social mobility in Chile in comparative perspective, American Sociological Review, vol. 70, No 3, Washington, D.C., American Sociological Association.

Torche, F. y G. Wormald (2004): Estratificación y movilidad social en Chile: entre la adscripción y el logro, serie Políticas sociales, No 98, LC/L.2209-P, Santiago de Chile, Comisión Económica para América Latina y el Caribe (CEPAL). Publicación de las Naciones Unidas, $\mathrm{N}^{\circ}$ de venta: S.04.II.G.32.

Torrado, S. (1994): Estructura social de la Argentina: 1945-1983, Buenos Aires, Ediciones La Flor.

Tortosa, J. (1992): La pobreza capitalista, Madrid, Tecnos.

Ugalde, P. y J. J. Prieto (2001): Caracterización de la clase media en Chile durante los noventa, informe preliminar, Santiago de Chile, Facultad de Ciencias Sociales, Universidad de Chile.

Valladares, L., E. Préteceille y otros (2005): Río de Janeiro en el viraje hacia el nuevo siglo, en A. Portes, B. y A. Grimson (comps.), Ciudades latinoamericanas. Un análisis comparativo en el umbral del nuevo siglo, Buenos Aires, Prometeo.

Vega Martínez, M. (1999): La clase media en transición: situación y perspectivas al finalizar el siglo veinte, Revista de ciencias sociales, $\mathrm{N}^{\circ}$ 86-87, San José, Universidad de Costa Rica.

Waldinger, R. y C. Feliciano (2004): Will the new second generation experience 'downward assimilation'? Segmented assimilation re-assessed, Ethnic and Racial Studies, vol. 27, № 3, Londres, Taylor \& Francis

Wilson, J. (1987): The Truly Disadvantaged: the Inner City, the Underclass and Public Policy, Chicago, University of Chicago Press.

Wormald, G., L. Cereceda y P. Ugalde (2002): Estructura de oportunidades y vulnerabilidad social: los grupos pobres en la Región Metropolitana de Santiago de Chile en los años 90, en R. Katzman y G. Wormald (coords.), Trabajo y ciudadanía. Los cambiantes rostros de la integración y exclusión social en cuatro áreas metropolitanas de América Latina, Montevideo, Cebra. 